\title{
El arzobispo de México, Lanciego Eguilaz, ante los problemas de adoctrinamiento de los indios
}

\author{
Rodolfo Aguirre SAlvador \\ Universidad Nacional Autónoma de México (México, México) \\ roagusal@unam.mx
}

Código ORCID: 0000-0003-1698-1264

\section{RESUMEN}

Una preocupación central del arzobispo de México José Lanciego Eguilaz fue la deficiencia que tenían los indios del conocimiento de la doctrina cristiana, considerando que ello ponía en peligro la salvación de sus almas. La Iglesia tridentina y los concilios provinciales encomendaron a los curas esa tarea, quienes, sin embargo, no siempre la cumplían. Entonces, el arzobispo dictó medidas de corto y mediano plazo, para solucionar la problemática: decretos para cada curato o doctrina, reforzamiento en la formación de los futuros curas y una reorganización parroquial. De esa forma, el prelado se dedicó a mejorar las instancias parroquiales para una mejor enseñanza de la doctrina a los indios. 
Palabras clave: José Lanciego Eguilaz, arzobispado de México, enseñanza de la doctrina, indios, parroquias

\section{The archbishop of Mexico, Lanciego Eguilaz, faced with the problems of indoctrination of the Indians}

\section{Abstract}

A central concern of the Archbishop of Mexico José Lanciego Eguilaz was the deficiency that the Indians had in the knowledge of Christian doctrine, considering that this endangered the salvation of their souls. The Tridentine Church and the provincial councils entrusted this task to the priests, who, however, did not always fulfill it. Then, the archbishop issued short and medium-term measures to solve the problem: decrees for each parish or doctrine, reinforcement in the training of future priests and a parish reorganization. In this way, the prelate dedicated himself to improving the parochial instances for a better teaching of the doctrine to the Indians.

KEYworDs: archdiocese of Mexico, teaching doctrine, Indians, parishes

\section{Presentación}

EN 1712 FELIPE V REALIZÓ SU PRIMER nombramiento arzobispal para la importante mitra mexicana, eligiendo al monje benedictino José Lanciego Eguilaz como encargado de llevar a buen puerto las diferentes encomiendas reales en la Iglesia novohispana. El nuevo arzobispo, en efecto, representó bien los intereses monárquicos en política eclesiástica: el cobro del subsidio eclesiástico, una mayor sujeción de las órdenes religiosas a las directrices monárquicas, el mejoramiento del seminario tridentino y de la formación de la clerecía, sin olvidarse de favorecer al alto clero local, sector en el que se apoyó para llevar adelante su mandato (Aguirre, 2012, pp. 321-347). 
Durante su gobierno en la mitra mexicana, entre 1712 y 1728 , Lanciego Eguilaz se dio a la tarea de conocer todos los problemas que aquejaban a su clero y su feligresía y, en especial, aquellos relacionados con la vida y la administración espiritual de los indios, quienes constituían la mayor parte de la población. Para paliarlos dispuso de todos los recursos a su alcance, siendo la visita pastoral su principal acción de gobierno pues, a través de ella, fue decidiendo criterios y acciones para el resto de su mandato.

Una preocupación creciente del prelado, a raíz de sus recorridos en las parroquias rurales, fue la deficiencia que advirtió en los indios del conocimiento de la doctrina cristiana, considerando que ello ponía en peligro la salvación de sus almas y los exponía a todo tipo de engaños y torpezas (Aguirre, 2016, I, pp. 155-521). Al respecto, la Iglesia tridentina y, en especial, los concilios provinciales indianos derivados, descargaron en los curas de almas la principal responsabilidad. Sobre la enseñanza de la doctrina los párrocos debían enseñarla personalmente, por una hora, los domingos y en fiestas, a todos los menores de doce años. ${ }^{1}$ A los niños indios les debían hablar en su propia lengua ${ }^{2}$ y establecer escuelas de castellano para aprender a leer y escribir, evitando ponerlos a trabajar a su servicio. ${ }^{3}$ El cura de indios debía conocer bien el catecismo del Concilio de Trento y enseñar los misterios de la fe, los mandamientos y los sacramentos. ${ }^{4}$ Dueños de obraje y encomenderos debían garantizar la enseñanza de la doctrina a los indios y a los mulatos de sus obrajes e ingenios de azúcar (Recopilación, 1681, lib. I, tít. II, ley $\mathrm{XI}$ ). Las audiencias debían cuidar que los indios fueran doctrinados, sin importar quejas de los clérigos (Recopilación, 1681, lib. I, tít. XIII, ley III). En la enseñanza de la doctrina en las visitas podían ser

\footnotetext{
1 Tercer Concilio Provincial Limense, sesión II, cap. 5.

2 Tercer Concilio Provincial Mexicano, libro I, tít. I, párrafo III.

3 Tercer Concilio Provincial Mexicano, libro I, tít. I, párrafo V.

4 Tercer Concilio Provincial Limense, sesión II, cap. 4.
} 
auxiliados, pero no sustituidos, por indios bien instruidos. ${ }^{5}$ Acosta criticaba que a los indios se les enseñara la doctrina de memoria y en castellano, lo cual consideraba ficticio (Acosta, 1954, lib. IV, cap. III), además de que se nombraba a los peores ministros para esas tareas (Recopilación, 1681, lib. I, tít. I, ley III).

Con estas bases canónicas el arzobispo Lanciego comenzó a dictar medidas de corto y mediano plazo, para solucionar esa problemática: decretos para cada curato o doctrina, reforzamiento en la formación de los futuros curas, así como un plan de reorganización parroquial que acercara más a los indios al cumplimiento de los designios tridentinos y del tercer concilio provincial mexicano. Paralelamente, su provisor de indios, José Ignacio Castorena y Ursúa, se destacó por instruir autos de fe de indios que tuvieron un impacto importante a favor de erradicar la idolatría (Lara, 2014, pp. 233-303). Todo indica que Lanciego y su curia se alinearon a una tendencia en otros obispados que buscó acabar con idolatrías en ciertas regiones indígenas, como lo actuado por el obispo de Oaxaca fray Ángel Maldonado, en Villa Alta, en los primeros años del siglo XVIII (Yannakakis, 2006, pp. 833-893), o bien la persecución que los dominicos y el obispo de Chiapa hicieron de los líderes en la doctrina de Cancuk durante una importante revuelta que pretendió acabar con el régimen español en 1712 (Vos, 2011, pp. 19-48). En la ciudad de México, poco después de esos acontecimientos que marcaron a los obispados en cuestión, el arzobispo Lanciego dio libertad a su provisor de indios para hacer demostraciones punitivas que complementaran sus visitas y decretos favorables a la reforma de la administración espiritual de los indios. Aún más, permitió a su provisor informar personalmente al rey sobre su accionar en contra de la ignorancia, la superstición y la idolatría de los indios. En carta del 3 de diciembre de 1715, el provisor Castorena informó a Felipe $\mathrm{V}$ sobre la política seguida en el arzobispado para salvaguardar la

5 Tercer Concilio Provincial Mexicano, libro III, tít. II, párrafo XII. 
salud espiritual de los indios y, en especial, sobre sus acciones contra la idolatría:

[...] habiéndome ejercitado por tiempo de siete años en el conocimiento de causas criminales que tocan al fuero eclesiástico y principalmente en las de mayor gravedad e importancia para la conversión y educación de los indios que son las de supersticiones, hechizos e idolatrías, de que habiendo sentenciado a varios en autos particulares me enseñó la experiencia que para la extirpación de estos execrables y continuados vicios entre los indios sería bien [...] hacer un auto en que saliesen a penitencia pública cinco reos indios cuyas causas estaban sustanciadas para que a ellos sirviese de enmienda y a los demás de ejemplo $[\ldots]{ }^{6}$

El provisor justificó que el auto de fe citado había sido necesario debido a la «rusticidad» de los indios, quienes más aprendían por la vista que por el oído. Además, el provisor propuso a la Corona que el auto de fe podría servir de «aliento» para los ministros encargados de educar a los naturales en los dogmas, así como para impedir los muchos pecados que por su «rústico entendimiento» cometían. ${ }^{7}$ Nada más oportuno en una época en que Felipe $V$ salía de una guerra de sucesión victorioso, durante la cual sus apologistas lo rodearon de una aureola de defensor de la verdadera religión en contra de la herejía de los austracistas, enemigos de la fe (Castellano, 2004, pp. 942-943).

Es claro entonces que para el gobierno del arzobispo Lanciego, la enseñanza de la doctrina y los autos de fe eran parte de un mismo objetivo. De esa forma, el prelado dejó el asunto de la persecución de idolatrías a su provisor de indios mientras que él se dedicó a mejorar las instancias involucradas en el correcto adoctrinamiento de los indios, tanto a corto como a mediano plazo. En las siguientes

6 Archivo General de Indias [AG], México, 817.

7 Otros estudios importantes sobre el asunto de la idolatría indígena en el siglo XVIII novohispano, además de los ya citados, son: Tavárez, 2012; y Chuchiak, 2014a, 2014b. 
páginas se da cuenta de esa labor, por otro lado, prácticamente desconocida en la historiografía sobre el arzobispado de México de la época de Felipe V.

\section{EL ENCUENTRO CON LOS FIELES Y LOS CURAS EN LA VISITA PASTORAL}

El arzobispo Lanciego se empeñó en conocer personalmente las condiciones en que cada cura desarrollaba su ministerio, para lo cual, entre 1715 y 1722, realizó nueve recorridos pastorales por todos los rumbos del arzobispado (Bravo y Pérez, 2016, I, pp. XLILVIII). Fue un gran esfuerzo por conocer de cerca el estado que guardaban y sus problemáticas, que no eran pocas, a dos siglos del establecimiento de la Iglesia en Nueva España, tarea ardua que el mitrado hizo patente a la Corona: «ha ejecutado personalmente la visita general de todo su arzobispado (de que no hay ejemplar por otro prelado) sin detenerse a la contrariedad de climas tan opuestos, frígidos y cálidos, ni en lo agreste y dilatado de su término». ${ }^{8}$

El prelado examinó personalmente, o por medio de su secretario, a los fieles sobre su conocimiento de la doctrina, en cada visita parroquial, preguntando a los niños y a los fiscales encargados de enseñarla (Aguirre, 2016, I, p. 167). El encuentro del arzobispo con los indios fue determinante para el resto de su mandato, al advertir las deficiencias que, desde su punto de vista, los indios tenían con respecto a los ideales tridentinos de conocimiento de la fe. De hecho, llegó a expresar al rey que el Tercer Concilio Mexicano no se aplicaba. ${ }^{9}$

En julio de 1717, luego de haber realizado su tercera visita pastoral, Lanciego advirtió a Felipe V que el principal problema era

8 AGI, México, 805, cartas y expedientes del arzobispo de México, de 1704 a 1724.

9 AGI, México, 805, carta del 22 de abril de 1721. 
la ignorancia de la doctrina en los indios, luego de doscientos años de conquistada la tierra. Consideraba que ello se debía a que los arzobispos habían visitado poco sus jurisdicciones por diferentes motivos, incluyendo que la Corona los había ocupado en otros asuntos, por la omisión de los párrocos y, también, por la flojedad y ociosidad de los indios, actitud que contagiaba a los curas, quienes se contentaban entonces con decirles misa, pero no les explicaban la doctrina. El prelado negó que los naturales fueran incapaces de entenderla cabalmente, pues aquellos que vivían con españoles la comprendían bien, pero que si no se hacía algo efectivo los indios seguirían en la misma situación. ${ }^{10}$

Las críticas a los curas y a los misioneros llegaron también a Felipe V en la correspondencia de la mitra. Así lo hizo el arzobispo, luego de su visita de 1720 a la Huasteca y a la custodia de misiones franciscanas de Tampico, al considerar que los indios tenían:

[...] poca frecuencia de doctrina; por lo general se vive más a lo animal que a lo racional, sobre que he encargado gravísimamente la conciencia a mis ministros y curas, así en la explicación frecuente de la doctrina para los adultos como la erección de escuelas de lengua castellana para la buena crianza de los niños y llega a tanto la desgracia, así en la sierra alta como en esta Huasteca, que he hallado parajes a donde ni se dan ni se piden los sacramentos y pueblos enteros donde aún a los adultos aunque sean gobernadores y alcaldes no se les da la sagrada comunión, contentándose los ministros con solo confesarlos una vez en el año y excusándose de la sagrada comunión por decir son incapaces, como si esta incapacidad no fuera culpabilísima en mis ministros. ${ }^{11}$

Ante todo esto, Lanciego se dispuso a responsabilizar a los actores que rodeaban a los indios para mejorar el conocimiento de la doctrina, meta complicada, pues implicaba destinar más recursos económicos y humanos a las tareas parroquiales que afectaban otros

10 AGI, México, 805, carta del 15 de julio de 1717.

11 AGI, México, 805, carta del 14 de agosto de 1720. 
intereses, tanto del clero parroquial como de gobiernos indígenas y de los hacendados incluso. Sin embargo, el prelado, convencido de la primacía de la salud espiritual de los naturales, dictó todos los decretos que consideró necesarios para lograrla.

En los registros de sus recorridos parroquiales el arzobispo expresó la decepción y preocupación que le causaba cerciorarse del atraso de los fieles en el conocimiento de la doctrina, ${ }^{12}$ para luego responsabilizar de ello a los curas. ${ }^{13}$ Luego de asentar estas faltas, salvo algunas excepciones, fue dictando diferentes decretos para enmendarlas, de acuerdo con lo que fue detectando en cada partido. En Xochitepec, doctrina franciscana enclavada en el valle de Cuernavaca, al sur de la capital novohispana, Lanciego hizo una fuerte amonestación al doctrinero:

[...] haber reconocido de dos años a esta parte en esta parroquia, considerable omisión, así en hacer la cuenta de los naturales para oír el santo sacrificio de la misa como en la explicación de la doctrina cristiana de donde nace, haber reconocido en la niñez y en la juventud considerable ignorancia en los misterios de nuestra santa fe católica, mandamos severísimamente a nuestro cura ministro enmiende esta omisión tan perniciosa, y todos los domingos y fiestas haga que a su presencia se haga la cuenta, así de la cabecera como de la visita y juntamente explique la doctrina cristiana en los referidos días de domingo, así en la cabecera como en los pueblos y haciendas a donde se fuere a decir misa. ${ }^{14}$

12 Aguirre (2016, I, p. 167), auto general de visita a la doctrina dominica de Tlalpan: «hemos visto por nuestros ojos con grande dolor de nuestro corazón en diferentes parajes, especialmente de haciendas, ranchos, obrajes y pueblos pequeños muchos adultos y aún casados, no saben persigna[rse], ya por rudeza, ya por la poca frecuencia que los curas y ministros tienen con los fieles para instruirlos en la doctrina cristiana».

13 Aguirre (2016, I, p. 215), auto de visita general de Xochitepec: «no saben persignarse, ya por su rudeza, ya por la poca frecuencia que los curas y ministros tienen con los fieles para instruirlos en la doctrina cristiana».

14 Aguirre (2016, I, pp. 486-487): «encargamos severísimamente a nuestro cura ministro, cese en la perniciosa omisión que ha tenido en exhortar a sus fieles la 
Lanciego criticó duramente a los doctrineros y a los curas el que ellos o sus tenientes dijeran dos o más misas en un solo día, con lo cual acortaban su estancia en los pueblos de visita y se olvidaban de enseñar la doctrina. Por ello, cuando halló a algún doctrinero que sí se esmeraba por la enseñanza de la doctrina, como sucedió en la doctrina dominica de Oaxtepec, ${ }^{15}$ no dudó en reconocerlo ampliamente, pues no fue lo común. Tanto los curas como sus tenientes debían darse el tiempo suficiente para enseñar antes o después de la misa y no dejar esa labor solo a los indios fiscales. En Santa Marta, ayuda de parroquia de la doctrina franciscana de San José de los naturales, como en muchas otras parroquias, Lanciego ordenó al respecto: «encargamos severísimamente a nuestro cura que todos los domingos explique la doctrina cristiana artículo por artículo y misterio por misterio» (Aguirre, 2016, I, p. 506). Además, tenían la obligación de explicarla en la lengua que hablaran los indios. ${ }^{16}$

Otro renglón en el que el arzobispo insistió mucho fue pedir a los doctrineros, con una feligresía abultada, tener más ayudantes,

observancia de las virtudes y reprenderles la corrupción de sus costumbres, de cuya omisión resulta la relajación del pueblo y aumento de los vicios que por todo derecho está obligado a extirpar con su doctrina y ejemplo, y en especial le reprendemos y afeamos la omisión en explicar a sus fieles la doctrina cristiana y misterios de nuestra santa fe católica, en que con gran dolor de nuestro corazón y después de quince años de cura, hemos hallado considerable atraso en la juventud».

15 Aguirre (2016, I, p. 271): «hemos reconocido la aplicación de nuestro cura ministro al cumplimiento de su obligación, por tanto, le damos las gracias de su buena administración y en especial de la explicación de la doctrina cristiana todos los domingos».

16 Aguirre (2016, I, p. 167), como lo dispuso en Tlalpan: «que en los pueblos o haciendas a donde se fuere a decir misa se haga todos los domingos la misma explicación, la cual en los sobre dichos pueblos y haciendas sea siempre en lengua mexicana». 
como sucedió en Tepoztlán. ${ }^{17}$ En Yautepec, en donde había tres frailes, Lanciego consideró que de acuerdo con el número de misas que se decían en la cabecera, en las visitas y en los trapiches, no eran suficientes esos ministros, por lo que ordenó poner más en el término de tres meses (Aguirre, 2016, I, p. 257). Para atajar rechazos de los curas sobre esta resolución, Lanciego criticó a aquellos que, teniendo suficientes obvenciones para pagar ayudantes, no lo hacían, como sucedió al doctrinero franciscano de Cuernavaca respecto a la administración espiritual de la visita de Xochitepec: «que la congrua que produce esta administración [...] alcanza al sustento de más ministros que puedan cumplir con las obligaciones referidas, por tanto, mandamos que dentro de tres meses, primeros siguientes, se pongan los ministros necesarios por nuestro cura ministro de la Villa de Cuernavaca» (Aguirre, 2016, I, p. 217). Lo mismo le pidió para la ayuda de Mazatepec (Aguirre, 2016, I, p. 228) e igual al doctrinero de Tlaltizapan (Aguirre, 2016, I, p. 246).

Además, Lanciego estrechó a los doctrineros a que sus coadjutores debían antes ser examinados en lengua y doctrina por la mitra, como lo dispuso en Jantetelco (Aguirre, 2016, I, p. 305) o en Zacualpan: «mandamos que para la buena administración de esta doctrina, ponga otro coadjutor de que necesita y éste sea de los aprobados por nos en suficiencia y lengua» (Aguirre, 2016, I, p. 315) En Cuautla, Jonacatepec, Jantetelco y Zacualpan, el prelado urgió a los doctrineros a destinar más ayudantes también para el mismo fin (Aguirre, 2016, I, pp. 285, 305). En el segundo partido dio instrucciones precisas sobre cómo debería actuarse en las visitas: «mandamos a nuestro cura ministro ponga otro coadjutor, para la administración y que el sacerdote que de su orden hubiere de ir a

17 Aguirre (2016, I, pp. 263-264): «en atención al crecido número de esta feligresía y ser toda de naturales [...] y no tener coadjutor de lengua [...] mandamos que dentro de tres meses de la fecha de este dicho nuestro cura provea de ministros bastantes para lo referido y explicación de la doctrina cristiana todos los domingos en que hallamos defectuosos a los naturales». 
decir misa a estos pueblos, se detenga hasta que se congreguen los individuos y que a todos les explique la doctrina cristiana» (Aguirre, 2016, I, p. 297). Lanciego incluso sugirió el método para enseñar la doctrina a los niños de una manera más efectiva: «encargamos no sea mucha la explicación de la doctrina, sino como a infantes, clara y poca y proponiéndola con algunos ejemplos materiales y atemperándose a su rudeza» (Aguirre, 2016, I, p. 392).

El arzobispo también impulsó más días para enseñar la doctrina y no solo cuando los curas celebraran misa; para ello, se debía antes instruir mejor a los indios fiscales y maestros de los niños, llamados «temastianes». En Tochimilco, Lanciego encargó «la conciencia así a nuestro cura como a sus coadjutores, elijan para este efecto el fiscal que fuere más de su satisfacción, examinándolo y reconociéndole» (Aguirre, 2016, I, p. 327). Los doctrineros debían examinar a los fiscales, quienes debían saber bien las oraciones y poder explicar los misterios de la fe, insistiendo que contar con estos ayudantes indios no eximía a los primeros de su enseñanza personal en los días de misa (Aguirre, 2016, I, p. 305). En Chalco, el mitrado ordenó al cura estar al pendiente de los indios fiscales que enseñaba la doctrina a los jóvenes: «que en los días de la semana de cuando en cuando baje a reconocer los muchachos y el modo con que el fiscal les pasa las oraciones, para que a su presencia se aviven» (Aguirre, 2016, I, p. 478). Misma disposición decretó en Coatepec (Aguirre, 2016, I, p. 492). En Tetela del Volcán, Lanciego designó incluso al temastian y ordenó al gobernador y fiscales indios garantizar la asistencia de los niños y las niñas a la enseñanza de la doctrina (Aguirre, 2016, I, pp. 339-340).

Los pueblos sujetos a las cabeceras parroquiales, llamados también «visitas», fueron parte también de las preocupaciones del prelado. Durante sus recorridos dispuso siempre decretos para mejorar la enseñanza y nombrar fiscales, como en San Juan, de la doctrina dominica de Tenango Tepopula (Aguirre, 2016, I, p. 430). En Tlalmanalco, de franciscanos, y pese a reconocerle al doctrinero 
su esmero en la enseñanza de la cabecera, le ordenó hacer lo mismo en las visitas y en las haciendas de la jurisdicción (Aguirre, 2016, I, p. 451). De hecho, atendiendo también el problema de la desatención de esos pueblos, Lanciego recordó a los curas y sus tenientes la obligación que tenían de explicar la doctrina, antes o después de las misas, como sucedió en Chimalhuacán Chalco (Aguirre, 2016, I, p. 403).

El arzobispo también recordó a los cabildos de indios y a los tenientes de alcalde mayor la obligación que tenían de ayudar a los curas para que todos asistieran a misa y a la enseñanza de la doctrina (Aguirre, 2016, I, pp. 348-349, 355). Así lo hizo saber al teniente de alcalde mayor en Tepoztlán: «se haga la cuenta de los naturales [...] y para ello se compelan los indios a que se junten y entren temprano sobre que encargamos al teniente de este lugar su obligación y que ayude al padre cura para este efecto» (Aguirre, 2016, I, p. 263). El arzobispo quiso establecer también instancias para la enseñanza de la doctrina en las haciendas, conciente de la importancia de estas entidades como núcleos de fieles a veces más importantes que los pueblos. En Tepetlixpa, por ejemplo, decretó «que en las haciendas a donde se fuere a decir misa se haga la misma explicacion por el mismo sacerdote que fuere a decirla y para la cotidiana enseñanza los dueños nombren uno de los sirvientes, el más ladino que sirva de fiscal y pase la doctrina cristiana a los demás» (Aguirre, 2016, I, p. 397).

En la región de Cuernavaca, Lanciego impuso a los dueños de las haciendas azucareras la obligación de poner encargados de repasar la doctrina a sus trabajadores, como en Xiuhtepec: «y para la cotidiana enseñanza los dueños de ingenios, haciendas o trapiches, nombren uno de los sirvientes o esclavos de ellas el más ladino para que pase la doctrina cristiana a los demás, declarando como declaramos ser esto muy de su obligación» (Aguirre, 2016, I, p. 202). En Oaxtepec, ordenó a los hacendados garantizar la doctrina también a los hijos de los esclavos, bajo pena de dar cuenta de su conciencia a Dios, pero también a los doctrineros y a la mitra (Aguirre, 2016, I, 
p. 272). En tanto, en la doctrina dominica de Yautepec, no muy lejos de Cuernavaca, el prelado reprendió duramente a los hacendados por impedir la enseñanza a los muchos fieles que la necesitaban, para cuyo remedio dictó medidas puntuales:

[...] que a los niños asi libres como esclavos nacidos en semejantes parajes hasta la edad de siete u ocho años, los inclinen y apliquen a la enseñanza del fiscal, por cuya cuenta corre esta obligacion $[. .$.$] que$ a los fiscales aprobados por nuestro cura ministro para dicha crianza no los puedan ocupar en otro ejercicio en aquel tiempo que estuviere determinado para la enseñanza [...] que de lo contrario daran cuenta a Dios de las almas de sus sirvientes que se pierden por la ignorancia de los misterios de nuestra santa fe por defecto de crianza cristiana que como padres de familia no tuvieren con sus sirvientes. $Y$ asimismo tenga una nómina puntual así de los adultos como niños que hubiere en semejantes parajes y que esta se entregue a nuestro cura ministro para que por ella tome la cuenta y se entere del aprovechamiento de la niñez $[\ldots] .{ }^{18}$

Lanciego ordenó establecer escuelas de castellano, antiguo deseo de la Corona y que el arzobispo retomó, considerando que la conservación de las lenguas indígenas era un obstáculo para consolidar la evangelización de las nuevas generaciones de indios. ${ }^{19}$ De ahí que insistiera en todos los partidos la creación de ellas, pues fueron muy pocas las que halló fundadas, como en Ozumba, ayuda de Tlalmanalco, en donde había una, encargando al doctrinero que la siguiera conservando (Aguirre, 2016, I, p. 412). Por provenir esta disposición de una real cédula, Lanciego hizo recaer la obligación de fundar esas escuelas en los alcaldes mayores y sus tenientes, sin hacer alguna propuesta sobre la fuente del salario de los maestros de castellano.

18 Aguirre (2016, I, pp. 255-256).

19 AGI, México, 805, carta del 15 de julio de 1717: «esta escuela de lengua castellana, cuya erección es mi principal asunto en esta tercera visita». 
Lanciego consultó con el virrey la conveniencia de establecer esas escuelas en cabeceras y pueblos importantes, pues si bien había hallado indios que decían bien las oraciones, en su lengua o en castellano, no las comprendían fácilmente y las repetían como papagayos; además, en realidad eran los temastianes, no tanto los curas, quienes se encargaban de hacer que las aprendieran de memoria. El prelado llegó incluso a ofrecer pagar el salario de un maestro indio de castellano en la doctrina dominica de Hueyapan, con tal de que los niños de ese partido aprendieran oraciones y la lengua hispánica; por ello, pidió al doctrinero designar al temastian o maestro indio para que la mitra le diera el título correspondiente (Aguirre, 2016, I, pp. 333-334).

En su afán por mejorar la vida espiritual de los naturales a partir de las instancias parroquiales, el arzobispo emprendió también la reforma de las cofradías y las hermandades, la mayoría dirigidas por indios. Durante sus visitas inspeccionó al menos 360 confraternidades distribuidas en 82 partidos. El prelado reafirmó de forma categórica su condición de comunidades de fieles regidas por la normativa canónica vigente, sujetas a la jurisdicción ordinaria solamente y cuyo principal fin era reforzar el culto público y las necesidades materiales de los curatos. Sin duda era importante porque se trataba de sujetar a toda la feligresía organizada en cofradías, a las instancias de la Iglesia secular y a comprometerlas con el culto parroquial. Lanciego no escatimó en emitir múltiples decretos para resolver problemas concretos de las asociaciones de fieles, pero señaló también directrices a futuro que guiaran a los cofrades, a los curas y a los jueces eclesiásticos (Aguirre, 2018, pp. 105-139).

Por ello se reafirmó que las cofradías, como entidades sujetas a la jurisdicción eclesiástica con funciones de culto y bienes espiritualizados, debían acatar las directrices de la mitra y que los curas podían, si lo consideraban conveniente, impulsar cambios en sus constituciones. Así, en la visita a la cofradía de morenos de Nuestra Señora del Rosario, en el real de Sultepec, instruyó al cura 
que de no ser convenientes las prácticas que tenían por norma, debía reunir a los cofrades para formar nuevas constituciones y remitirlas al arzobispo o al provisor y vicario general para su aprobación (Aguirre, 2016, II, p. 222). Para la mitra, la noción de autonomía de las cofradías carecía de sentido en el marco de la potestad ordinaria a que estaban sujetas. Por supuesto que, a esta posición, se oponía la tendencia de diversas cofradías y sus mayordomos a actuar sin rendir cuentas a ninguna autoridad eclesiástica, aun a sabiendas de que estaban sujetas a su jurisdicción.

Más allá de esta serie de decretos específicos para las parroquias, Lanciego deseaba soluciones más generales, para lo cual, en abril de 1721, anunció al rey su decisión de convocar a un sínodo diocesano que fuera ejemplo y sirviera de modelo para el resto de los obispados novohispanos. Ese sínodo debería atender a los grandes problemas que vislumbró en el arzobispado, a saber: «solicitaré se renueve la observancia del concilio mexicano y se prevendrán las constituciones más conducentes para la reformación del clero, administración de los santos sacramentos y corrección de costumbres de los fieles, todo lo cual podrá servir de pauta para las demás diócesis a menos expensas». ${ }^{20}$

Para realizar el sínodo sin dificultades pidió protección del rey y la recomendación del virrey y demás altas autoridades de Nueva España. Para agosto de ese mismo año, Lanciego insistió al rey de la necesidad, ya no solo de hacer el sínodo sino de consultar con el papa varios asuntos de sumo interés, pues había gran necesidad de «restablecer y reparar la disciplina cristiana y eclesiástica, especialmente en un reino donde sus naturales gozan aun los privilegios de neófitos, habiendo llegado a tanto nuestra flaqueza que oigo decir no estar en uso ni observancia este nuestro concilio mexicano». ${ }^{21}$ Lanciego insistió en que el eslabón más débil de la Iglesia novohispana eran los indios

20 AGI, México, 805, carta del 22 de abril de 1721.

21 AGI, México, 805, carta del 19 de agosto de 1721. 
pues seguían siendo neófitos, a dos siglos de la conquista. Sin embargo, el sínodo nunca llegó a realizarse.

En 1722, luego de haber terminado sus visitas pastorales, Lanciego hizo un balance general del clero parroquial y la feligresía, que expresó a Felipe V. Para el prelado, en tono pesimista, nada de los decretos de la visita de su antecesor Aguiar y Seixas, de la década de 1680, se había practicado «ni en la explicación de doctrina cristiana ni en la observancia del arancel de los derechos parroquiales ni en aquel conocimiento de los misterios de nuestra santa fe, necesarios para la salvación de los hijos». ${ }^{22}$ De ahí que encomiara la visita pastoral como factor que enmendaba la tibia actitud de los curas en la administración espiritual. Para estos últimos, el prelado tenía también propuestas, convencido de que la salvación de la feligresía dependía en gran medida de buenos sacerdotes.

\section{Formar MEJORES CURAS}

En Trento, el concilio procuró hacer frente a fuertes críticas sobre la vida no ética del clero, la ilegitimidad de la jerarquía católica o la ignorancia de los clérigos. ${ }^{23}$ Por ello se abordaron tres aspectos básicos: el perfil del sacerdote ideal, la creación de seminarios para su educación y los mecanismos para la ordenación sacerdotal. Respecto a los seminarios, el concilio estableció las directrices que debían seguirse para lograrlo: debían fundarse cerca de las catedrales y con recursos de diferentes rentas eclesiásticas que el concilio dejaba a la discreción de cada prelado organizar. ${ }^{24}$

EnNueva Españalas dificultades para formarconvenientemente al clero secular se dieron desde el siglo XVI, y para principios del

22 AGI, México, 805, carta del 10 de julio de 1722.

23 Concilio de Trento, sesión XXIII, «El sacramento del orden».

24 Concilio de Trento, sesión XXIII, capítulo XVIII, «Se da el método de erigir seminario de clérigos y educarlos en él». 
XVIII seguía habiendo quejas y críticas. Al respecto, el proyecto arzobispal de Lanciego para la reforma de la vida espiritual de su feligresía, y en especial de los indios, no se limitó a los decretos de su visita pastoral, sino que también lo vinculó con la reforma del clero. Como era su tendencia, Lanciego expresó en 1715 a Felipe V su diagnóstico de la clerecía del arzobispado con duras palabras, a tono con las que usó para describir la situación espiritual de los indios: «he reconocido en mi clero considerable multitud y gran pobreza, $y$ lo que es peor, mezclado de sujetos de padres no conocidos, cuyo pernicioso efecto resulta de la indiscreción, con que a bulto, y sin distinción, se ordenan muchos en la sede vacante más por empeños y motivos temporales que por divina vocación». ${ }^{25}$

Con base en este panorama percibido, el arzobispo se dispuso a lograr cambios importantes con tres acciones principales: el fortalecimiento del seminario conciliar de México, de reciente creación; una mayor exigencia en la ordenación sacerdotal; y, finalmente, impulsar a clérigos mejor capacitados para administrar en lenguas indígenas.

En Nueva España, fue en el tercer concilio de 1585 cuando se decretó la creación de seminarios en las diócesis. ${ }^{26}$ No obstante, las fundaciones fueron lentas, al igual que en el resto del mundo hispánico, debido a la falta de rentas y la presencia de colegios y universidades en donde se formaba el clero secular. El de México se fundó en 1689, bajo el impulso del arzobispo Aguiar y Seixas, pero abrió sus puertas hasta 1697, con dieciséis colegiales de erección, cuatro de ellos hijos de caciques (Menegus y Aguirre, 2006). El nuevo colegio fue un proyecto del alto clero secular, encabezado por

25 AGI, México, 805, carta al rey del 3 de abril de 1715.

26 Tercer concilio provincial mexicano, libro I, título I, párrafo II: «que los obispos trabajen con toda la actividad de que son capaces en fundar esta clase de seminarios, y en hacerlos duraderos, luego que se hayan creado, según la posibilidad de cada una de sus diócesis, y cumpliendo exactamente el decreto del concilio de que se ha hecho mérito». 
su prelado y que tuvo como meta central ser el principal semillero de clérigos. Lanciego Eguilaz también se echó a cuestas regularizar la vida de esta institución que pronto rivalizó con el célebre colegio jesuita (Aguirre, 2012, pp. 32-44). La consolidación del seminario fue una realidad para la tercera década del siglo XVIII, a pesar de la rivalidad con los jesuitas de San Ildefonso y las dificultades de financiamiento. La demanda creciente de estudios y órdenes sacerdotales en el arzobispado lo hacía un proyecto viable.

El fortalecimiento del seminario fue una tarea difícil para Lanciego, pero inexcusable, ante los aires de renovación clerical en Madrid, luego de la guerra de sucesión. Consiente de todo ello, el arzobispo dedicó atención especial a mejorar la docencia y las finanzas del seminario, considerando que era «la principal escuela donde se han de formar los niños en letras y santidad para proveer la Iglesia de ministros idóneos y por eso estimarlo yo como una de las principales joyas que tiene mi sagrada mitra» (Chávez, 1996, I, p. 210).

El seminario conciliar tuvo también el apoyo de la universidad de México, institución ligada desde el siglo XVI a los intereses del alto clero secular del arzobispado, pues les permitió incidir mejor en la formación de los nuevos sacerdotes y depender menos del poderoso colegio jesuita. Un factor determinante para dar estabilidad al nuevo seminario fue contar con las aportaciones de ambos cleros, especialmente de los curatos y las doctrinas, como lo señalaba el concilio de Trento (Aguirre, 2012, pp. 45-54). De paso, la mitra acrecentó su autoridad ante las órdenes mendicantes, al lograr que colaboraran económicamente.

La contribución del seminario a la renovación del clero secular y a su aumento fue indudable. Para mediados del siglo XVIII varios cientos de alumnos de ese seminario se habían graduado en la universidad y una buena parte de ellos había ingresado al clero secular; junto con la mitra, habían hecho del colegio el segundo en importancia por el número de alumnos y graduados, no solo del arzobispado sino de todo el virreinato en un periodo de tiempo 
relativamente corto, superando incluso a los de Puebla (Aguirre, 2002, pp. 37-42). Por lo concerniente a las demandas de la Corona para renovar al clero, Felipe $V$ podía estar satisfecho con las acciones de Lanciego a favor del seminario tridentino.

En consonancia con sus decretos de visita sobre que la explicación de la doctrina a los indios debería ser en sus idiomas, en la capital el arzobispo Lanciego se dio a la tarea de impulsar la formación de clérigos lenguas. Aunque desde el siglo XVI se ordenó la castellanización de la población indígena, en la práctica las órdenes religiosas se dieron a la tarea de aprender las lenguas para facilitar la conversión religiosa y la comunicación. Los detractores del clero regular argumentaron que este las preservaba para apartar a los indios de los españoles y consolidar su poder. Otra acusación en contra de las lenguas indígenas fue que los indios conservaban así sus antiguos ritos e idolatrías, en detrimento de la fe católica. Los religiosos las defendieron argumentando que mediante ellas los indios podían entender mejor la fe cristiana y que era obligación del clero aprenderlas. Con todo, la Iglesia en su conjunto acabó por aceptar que, puesto que la castellanización de los nativos llevaría mucho más tiempo del previsto, lo mejor era fomentar la formación de clérigos lenguas.

Lanciego fue coherente con esa tendencia secular y con las realidades lingüísticas del arzobispado, pues en cuarenta y ocho curatos seculares predominaba el náhuatl, en veinte el otomí, en doce ambos idiomas, en seis el mazahua, en tres el huasteco y en uno el matlatzinca. En esa misma proporción se ordenaban los clérigos lenguas. Los curatos considerados de lengua castellana solo eran los del centro de México: catedral, San Miguel, San Pablo, San Sebastián, Santa Catarina Mártir y Santa Veracruz, más el real minero de Pachuca y el puerto de Acapulco, en donde se hablaba también el náhuatl. ${ }^{27}$

27 AGI, México, 338, año de 1670. 
Aunque el arzobispo impulsó las escuelas de castellano, según se ha mencionado antes, también reforzó la ordenación de clérigos lenguas, conciente de que seguían necesitándose. Así lo reflejan los registros de más de dos mil exámenes para la ordenación de clérigos en su mandato, en donde se exige a todos los ordenantes, en principio, el conocimiento mínimo de una lengua. ${ }^{28} \mathrm{Si}$ nos atenemos solo al rubro del título en que se ordenaron los clérigos entre 1717 y 1727, se aprecia que el 54.8 \% expresó conocer una lengua. Paralelamente, la mitra fomentó también la ordenación de indios clérigos. En carta al rey, de abril de 1722, Lanciego destacó que los impulsó para que «después de prácticos en nuestro idioma y en las ciencias sean más útiles los que sobresalieren a la conversión y educación de aquellos pobres indios que los mismos españoles por ser tan natural el amor a los propios y que en esta consecuencia ocupen también curatos los doctos». ${ }^{29}$

A nivel general, Lanciego buscó aumentar las exigencias para quienes deseaban convertirse en sacerdotes, dadas las fuertes críticas sobre la falta de idoneidad de la clerecía, tanto en España como en América. A principios del siglo XVIII, algunos ministros de Felipe $\mathrm{V}$ criticaron la falta de vocación y de preparación del clero, agregando que se habían relajado los requisitos para obtener las órdenes sacerdotales (Domínguez, 1992, II, pp. 54-55). Aunque en el Concilio de Trento se especificaron bien los requisitos, sin embargo, no se cumplían necesariamente. Estas preocupaciones en la corte madrileña hicieron eco en prelados de Felipe V, como Lanciego Eguilaz, quien puso manos a la obra también. ${ }^{30}$

28 Archivo General de la Nación de México (en adelante: AGNM), Bienes Nacionales, leg. 1271, exp. 1.

29 AGI, México, 805, carta del 13 de abril de 1722.

30 En Yucatán, el obispo Juan Gómez de Parada, quien gobernó por la misma época que Lanciego Eguilaz, también realizó serios intentos por responder al llamado de Madrid sobre cumplir con las exigencias conciliares en las ordenaciones sacerdotales (Solís, 2003, p. 17). 
Un informe del arzobispo a la Corona señaló las deficiencias halladas sobre ordenación sacerdotal durante la sede vacante que lo precedió. ${ }^{31}$ Aunque durante ella, entre 1708 y 1712, el cabildo eclesiástico nombró una junta de órdenes, para revisar los casos problemáticos de clérigos que se iban a ordenar, en la práctica, hubo un gran número de nuevos clérigos. ${ }^{32} \mathrm{El}$ prelado concluyó que esa junta fue muy flexible en los requisitos pedidos a los clérigos.

Pero Lanciego Eguilaz no se conformó con verter críticas $y$, en consecuencia, se propuso, realizar ajustes para mejorar el perfil eclesiástico de los aspirantes al sacerdocio, cumplir con los requisitos canónicos y alinearse a las preocupaciones de Madrid. Se nombraron más examinadores sinodales, generalmente curas de la ciudad de México, que revisaron los conocimientos de gramática latina, teología moral, doctrina cristiana (evangelios, catecismo, breviario de párrocos) y lenguas indígenas. ${ }^{33}$ Además, fueron nombrados examinadores de lenguas minoritarias, como en 1722, cuando Nicolás de Vargas Machuca, catedrático de la lengua en la universidad, fungió como examinador de otomí, ${ }^{34}$ o Francisco de Estrada, quien examinó a cuatro clérigos en el idioma mazahua. ${ }^{35}$

Un libro de registro de exámenes, de 1717 a 1727, nos brinda una mejor idea sobre lo que sucedía en los sínodos del palacio

31 AGI, México, 805, carta del 3 de abril de 1715.

32 AGNM, Bienes Nacionales, leg. 236, exp. 5.

33 AGNM, Bienes Nacionales, leg. 41, exp. 6, ff. 39-39v.

34 AGNM, Bienes Nacionales, leg. 1271, exp. 1.

35 AGNM, Bienes Nacionales, leg. 1271, exp. 1, año de 1722 y leg. 41, exp. 6, f. 137. En otros casos, los aspirantes eran enviados con examinadores eventuales (podría ser un cura experto, por ejemplo), cuando había que hacerles exámenes especiales, ya sea canto, oraciones de misa, entre otros. Juan Antonio Fábrega examinó en canto y oraciones de misa a algunos aspirantes a presbíteros que le envió el arzobispo. 
arzobispal. ${ }^{36} \mathrm{El}$ documento está conformado por 2,153 registros de igual número de exámenes, de los cuales el $54 \%$ fueron aprobatorios, mientras que el $29 \%$ fueron reprobatorios. Esto demuestra que para Lanciego la ordenación sacerdotal no debía ser un mero trámite, ni que todo aquel que así lo deseara tenía garantizadas las órdenes sacerdotales.

Los orígenes sociales del clero secular fue otro rubro atendido por el arzobispo Lanciego, quien trató de frenar la ilegitimidad entre sus miembros (Aguirre, 2000, p. 78). En consecuencia, cuidó mucho de que los ordenantes demostraran ser hijos legítimos y de orígenes sociales aceptables. Para ello, se pedía a los clérigos dos comprobantes: una certificación de la fe de bautismo del cura del lugar de nacimiento y la información de limpieza y legitimidad sustentada por dos o tres testigos de buen nombre. En un libro de exámenes de 1717 a 1727, la primera cualidad que se anotaba de los clérigos era sobre su legitimidad, demostrada con la presentación de la fe de bautismo y las declaraciones de tres testigos. Prácticamente no hay registros en el libro que omitan ese requisito, lo cual confirmaría la preocupación de las autoridades eclesiásticas pues en esa época se presenciaban en la ciudad de México altas tasas de ilegitimidad, tanto en los españoles como en los mestizos (Gonzalbo, 1998, p. 178). Por supuesto que no se puede descartar que varias fes de bautismo estuvieran alteradas. Pero la apuesta de reforma de Lanciego no se limitó a mejorar la formación sacerdotal en el arzobispado, sino que inició también la de las parroquias, que seguía teniendo como centro la salvación de los fieles.

36 AGNM, Bienes Nacionales, leg. 1271, exp. 1. Esta fuente destaca por su escasez, pues hasta ahora no he hallado referencia sobre una similar para otros periodos arzobispales del siglo XVIII. 


\section{Proyectos para reorganizar la administración parroquial}

Durante su mandato, Lanciego también fue ideando cambios importantes en la estructura parroquial del arzobispado que dieran como resultado garantizar una vida cristiana aceptable de los indios. Para lograrlo, centró sus planes en tres ejes: aumentar el número de ministros espirituales, crear nuevas parroquias de menos fieles y sujetar a todos los curatos seculares, doctrinas y misiones a una mayor supervisión de la mitra. Fue una tarea complicada por cuanto debió enfrentar diferentes oposiciones e inercias de ambos cleros, pero aun así lo intentó.

Lanciego insistió en poner tenientes de cura fijos en pueblos de visita con gran feligresía que pudiera pagar su salario: «que se viva con los indios y sobre ellos para que tengan persona a quien venerar y temer con cuya presencia se recelen y desvíen de sus torpezas, embriagueces, supersticiones y aun idolatrías». ${ }^{37}$ Lanciego llamó la atención ante Felipe $\mathrm{V}$ sobre la oposición de los curas para pagar más ministros:

[...] tampoco me hace fuerza el que poniendo ministros en pueblos de vecindad y suficiente congrua se menoscabe el recibo, y aumentando ministros crezca el gasto, porque esto sería anteponer el interés a la salvación de las almas, lo cual es indigno de un espíritu cristiano, cuanto más religioso sea cierto que pueblos de indios que rinden congrua para seis ministros y no se les ponen más de tres o cuatro son perjudiciales en los dos o tres ministros que se les usurpan $[\ldots]^{38}$

Este asunto fue incluso consultado por Lanciego en Roma, pidiendo poderes especiales para obligar a los superiores religiosos a aceptar que se pusieran más vicarios en los pueblos donde hicieran falta. ${ }^{39}$

37 AGI, México, 805, carta del 15 de julio de 1717.

38 AGI, México, 805, carta del 15 de julio de 1717.

39 AGI, México, 817, sobre instancias del arzobispado de México, 1702-1733. 
En otra misiva a Felipe V, Lanciego denunció la discrecionalidad de los doctrineros para poner y quitar ayudantes y vicarios en pueblos de visita, mismos que no necesariamente están capacitados para administrar espiritualmente, para lo cual propuso dos soluciones: erigir nuevas parroquias para poner curas mejor formados, o bien que la mitra pudiera examinar previamente a todos esos ayudantes, en concordia con los religiosos, para evitar pleitos. ${ }^{40}$

La división de curatos y doctrinas para mejorar la atención espiritual de los fieles fue otro proyecto de Lanciego, por lo cual pedía a la Corona facilitar los procesos legales para lograrlo. En carta del 6 de abril de 1719, el prelado solicitó a Felipe V no permitir que se le pusieran dificultades a la mitra para dividir parroquias y que todo quedara solo en manos de los arzobispos y los virreyes:

[...] convendrá que en todo se difiera al dictamen de este y a la consulta que hiciere a vuestro virrey, sin dar lugar a más dilación, porque de lo contrario serán inútiles las grandes incomodidades que he padecido en mis cinco visitas, reconociendo personalmente las asperezas y distancias de los pueblos, todo a fin de darles la más cómoda administración y ver por mis ojos que en algunos parajes se me mueren los hijos sin sacramentos y si para obviar estos tan gravísimos inconvenientes quiero dividir alguna parroquia o poner ministros a donde convenga, nunca lo podré conseguir si se consienten estos recursos y dilaciones y se obliga a los prelados a que formen procesos de informaciones y diligencias para lo cual los prelados no tenemos tiempo ni vida. ${ }^{41}$

En ese mismo año, Lanciego insistió al rey sobre la utilidad de dividir las grandes parroquias para lograr una mayor cercanía de los curas con los fieles. Agregó que esto último podía agilizarse si se pasaba por alto los trámites que se acostumbraba pedir para dividir, y contando solo con «la consulta que sobre ellos hiciese a mi vice patrón, sin dar lugar a más dilación, porque de lo contrario serían

40 AGI, México, 805, carta del 16 de abril de 1719.

41 AGI, México 805, carta de Lanciego al rey, del 6 de abril de 1719. 
inútiles las grandes incomodidades que había experimentado en las referidas visitas». ${ }^{42}$ En Madrid, se contestó al arzobispo que si contaba con el visto bueno del virrey y de acuerdo a la normativa tridentina, podía erigir las escuelas y las parroquias que tuviere por convenientes.

Respecto a las misiones de la custodia de Tampico, jurisdiccionalmente pertenecientes también al arzobispado, Lanciego no solo quiso mejorar su administración espiritual, sino que impulsó su conversión a doctrinas para poder ejercer más atribuciones. A raíz de su visita en 1720, el arzobispo constató que los ministros de las misiones de Tampico carecían de presentación del virrey o de algún arzobispo, violando las leyes del real patronato al respecto, sobre todo la ley 3, título 15, del libro I de la Recopilación de leyes de Indias. ${ }^{43}$ Aunque esta ley no mencionaba específicamente a los misioneros, el prelado interpretó que debían tener igual tratamiento que los doctrineros. Así, el arzobispo propuso al virrey decretar la conversión de las misiones en doctrinas, para seguir todos los requisitos de presentación de ministros. El abogado fiscal del virrey opinó que, si bien era innegable que la población de las misiones había aumentado considerablemente, sobre todo de gentes de razón, y ello justificaría su transformación a doctrinas, antes había que pedir al provincial franciscano si tenía algo que alegar al respecto. ${ }^{44} \mathrm{El}$ virrey estuvo de acuerdo y así lo ordenó. Aunque no

42 AGNM, Reales Cédulas Originales, volumen 41, expediente 23.

43 En la parte central de esa ley se específica que: «Ordenamos y mandamos que en cuanto a remover y nombrar los provinciales y capítulos de las religiones, religiosos doctrineros, guarden y cumplan lo que está dispuesto por las leyes del patronazgo real de las Indias, sin ir ni pasar contra ello, en forma alguna. Y demás de esto, siempre que hubieren de proveer algún religioso para doctrina que tengan a su cargo, ora sea por promoción del que la sirviere, ó por fallecimiento ó otra causa, el provincial y capítulo hagan nominación de tres religiosos, los que les parecieren más convenientes para la doctrina, sobre que les encargamos las conciencias, y esta nominación se presente ante vuestro virrey, presidente o gobernador».

44 AGNM, Clero Regular y Secular, vol. 93, f. 197. 
sabemos la opinión precisa del provincial, es seguro que se negó al cambio de estatus, pues en informes de 1743 aún eran misiones esos centros.

Paralelamente, Lanciego emprendió la tarea de ampliar la jurisdicción ordinaria en las doctrinas mediante jueces eclesiásticos territoriales. La autoridad de los obispos fue cuestionada desde el siglo XVI por franciscanos, agustinos y dominicos, por lo que los primeros tuvieron que echar mano de múltiples recursos a lo largo de los años para imponer su autoridad, sancionada por el derecho canónico y el Concilio de Trento. ${ }^{45}$ Uno de esos recursos fue precisamente la figura del juez eclesiástico, cuya principal función fue extender la jurisdicción de los obispos en las parroquias y doctrinas de sus respectivas jurisdicciones diócesis.

La cuestión de los jueces eclesiásticos fue objeto de atención de los consejeros del primer rey Borbón. En 1701 se puso fin a las largas disputas que durante más de un siglo protagonizaron los obispos y las órdenes religiosas por el asunto de la supervisión de las doctrinas de indios. En cédula del 2 de octubre de ese año, el monarca expresó que ninguna ley, canónica o real, limitaba a los obispos la facultad de subdelegar las visitas de los religiosos a discreción, y que, en cuanto al nombramiento de vicarios foráneos, los obispos podían nombrarlos sin obstáculo. ${ }^{46}$

Fue el arzobispo Lanciego quien sacó más provecho de esa cédula y, en consecuencia, nombró jueces eclesiásticos para todas las regiones del arzobispado, incluyendo aquellas dominadas por religiosos. En algún momento previo a 1721, Lanciego Eguilaz solicitó al rey revalidar la cédula de 1701, argumentando que, aunque había intentado lograr la quietud de los frailes en su jurisdicción, ellos no lo permitían «en perjuicio de las regalías y autoridad de su

\footnotetext{
$45 \mathrm{Al}$ respecto pueden consultarse los recientes trabajos en la obra colectiva coordinada por Martínez y Cervantes, 2005.

46 AGNM, Bienes Nacionales, leg. 1285, exp. 23.
} 
mitra». ${ }^{47}$ En vista de ello, logró que Felipe V confirmara la cédula de 1701, ordenando a todos los obispos sufragáneos la observaran y cumplieran, «a cuyo fin se os remiten los que pertenecen a vuestros sufragáneos, para que por vuestra mano lleguen a las suyas, y tengan el debido cumplimiento que conviene a mi servicio»». ${ }^{48}$ Ya desde sus visitas pastorales, según se mencionó, Lanciego había ordenado a sus jueces eclesiásticos vigilar que los doctrineros cumplieran con la administración de todos los sacramentos. ${ }^{49}$

En 1722 Lanciego informó al rey que era importante reafirmar, ante todos, el derecho que los prelados ordinarios tenían para nombrar vicarios foráneos y visitadores; particularmente, eran necesarios para hacer cumplir los decretos de su visita pastoral. Finalmente, acusaba a los religiosos de no querer reconocer «otro visitador ni otro juez eclesiástico que el regular, eximiendo al prelado ordinario de todo el gobierno y jurisdicción eclesiástica de dichos curatos, lo cual dejo a la profunda consideración de VM». ${ }^{50}$

A principios de 1723, con ocasión de cumplir con la recaudación de un subsidio eclesiástico, otorgado por Roma en 1721, el arzobispo Lanciego envió una carta cordillera de instrucciones a un total de noventa y un jueces eclesiásticos, incluyendo a doce que solo tenían jurisdicción sobre doctrinas de religiosos, en las que vivía una gran parte de la población indígena del arzobispado. ${ }^{51} \mathrm{Al}$ parecer, antes de este año, no existió una cantidad así de jueces eclesiásticos, quienes actuaron como brazos ejecutores de las órdenes del monarca y de su prelado, recibiendo incluso una compensación económica por sus tareas de recaudación del subsidio. ${ }^{52}$

47 AGNM, Bienes Nacionales, leg. 1285, exp. 23.

48 AGNM, Bienes Nacionales, leg. 1285, exp. 23.

49 AGI, México, 805, carta del 14 de agosto de 1720.

50 AGI, México, 805, carta del 19 de julio de 1722.

51 Archivo Histórico del Arzobispado de México, caja 36, exp. 15.

52 AGNM, Bienes Nacionales, leg. 739, exp. 12. 
Después de haber intentado, sin mucho éxito, dividir doctrinas, nombrar más ayudantes de cura y convertir misiones en doctrinas, Lanciego se aprestó a una reforma de mayores alcances: la secularización de sesenta doctrinas del arzobispado. Aunque entre 1680 y 1720 se crearon más de veinte curatos seculares (Aguirre, 2008, pp. 487-505), ello no resolvió sustancialmente el problema de generalizar parroquias de menor magnitud. El arzobispo estaba al tanto sobre la reciente secularización de doctrinas en el obispado de Oaxaca. Varios puntos que el obispo fray Ángel Maldonado tocó en sus misivas parecen haber influido en acciones posteriores del arzobispo. ${ }^{53}$

Lanciego envió a su secretario, José Ansoain y los Arcos, como procurador a Roma en 1721, para tratar varios asuntos de las doctrinas y en especial el de la secularización. ${ }^{54}$ Este último asunto provocó mucha molestia en Madrid, pues al parecer Lanciego omitió consultar específicamente el traspaso de sesenta doctrinas. Atentos a esto, los franciscanos, con amplia experiencia luego de dos siglos de luchar por conservarlas, acusaron al arzobispo de menospreciar el real patronato al negociarlas directamente ante el papa. Este argumento fue exitoso pues el monarca y sus consejeros fueron muy sensibles a la acusación de omisión del real patronato, «la joya más preciosa que adorna la real corona», como expresara un virrey (Escamilla, 2001, p. 167) y, en consecuencia, olvidándose del objetivo central de Lanciego, llamaron a cuentas a su secretario a Madrid, ${ }^{55}$ con lo cual el proyecto de secularización no pasó adelante ya.

\section{REFLEXIONES FinALES}

Como otros obispos y autoridades novohispanas de su época, el arzobispo Lanciego Eguilaz estuvo atento también al problema de

53 AGNM, Bienes Nacionales, leg. 472, exp. 3.

54 AGI, México, 703.

55 AGI, México, 817. 
la idolatría indígena en su jurisdicción. Sin embargo, la manera como lo enfrentó fue un tanto diferente a otros mitrados. Por un lado, dio libertad a su provisor de indios, Juan Ignacio Castorena Ursúa, de dirimir y resolver las denuncias contra los idólatras, así como realizar autos de fe que tuvieran impacto en la población, especialmente la indígena. Incluso permitió al provisor enviar informes directamente sobre el asunto a Madrid; consideramos que ello no fue casual, sino una estrategia tanto para agradar a un rey que se había declarado enemigo de la herejía y defensor de la verdadera fe durante la guerra de sucesión, como para la promoción de Castorena, quien sería finalmente promovido a la mitra de Yucatán.

En tanto, el arzobispo Lanciego acometió la problemática indígena desde una óptica menos punitiva y más constructiva: esto es, no señalar solo a los indios como culpables de su alejamiento o desconocimiento de la verdadera fe, sino que fue más crítico con la Iglesia misma y hasta con la monarquía. Con esta última porque expresó al rey que sus antecesores habían ocupado a los prelados en otros asuntos que les impidió conocer mejor y resolver los problemas espirituales de la feligresía, algo que Felipe $\mathrm{V}$ también hizo.

Pero, sin duda, el prelado de quien nos hemos venido ocupando fue más insistente en el problema del mal adoctrinamiento de los indios en sus parroquias, al convertirlo en asunto central de sus visitas pastorales. Para el prelado, los primeros responsables de ello era el clero parroquial, quienes no se habían hecho responsables de garantizar la salud espiritual de los naturales, abandonándolos a su rusticidad, ignorancia y pecados. De ahí que una buena parte de los decretos que dejó asentados en los autos de visita giraran en torno a reconvenir a los curas y sus ayudantes para ocuparse permanentemente de enseñar la doctrina a los indios, fijando incluso la rutina que debían seguir: los domingos correspondía personalmente hacerlo a los ministros y entre semana a los fiscales y temastianes. Pero estos últimos debían ser antes bien aleccionados y estar también vigilados en su accionar. 
Igualmente, Lanciego pidió que en todas las parroquias se establecieran escuelas de castellano, haciendo responsable de ello a los alcaldes mayores y sus tenientes. La apuesta del arzobispo fue que, en la medida en que los naturales supieran la lengua española, podrían entender mejor la doctrina y, por tanto, estar en mejores posibilidades de salvar sus almas y vivir cristianamente. Por su parte, los gobiernos de indios también debían ayudar a los curas a garantizar la asistencia de los indios a la doctrina, especialmente la de los niños. Finalmente, los hacendados, como patrones de muchos naturales asentados en sus explotaciones, fueron también advertidos de su obligación de darles el descanso dominical para que pudieran asistir a misa y a la doctrina. Incluso el arzobispo les ordenó designar a un peón bien instruido como maestro de doctrina de sus trabajadores. Como es posible advertir, la apuesta del prelado fue involucrar a un sector más amplio de seglares como auxiliares de los curas en lo que para él era central: el buen adoctrinamiento de los naturales.

Pero Lanciego no se conformó con estas medidas para cada parroquia o misión, sino que intentó impulsar una reorganización parroquial para mejorar la administración espiritual de la feligresía: subdividir aquellas que tuvieran mucha población, establecer más ayudas o vicarías con ministros fijos, convertir las misiones en doctrinas e incluso secularizar sesenta de estas últimas, con el fin de que la mitra tuviera más jurisdicción. Sin embargo, no logró mucho al respecto, pues los curas se opusieron a dividir sus curatos o a pagar más ayudantes, así como los religiosos defendieron con éxito el statu quo de sus partidos.

No dejó tampoco de señalar los defectos en la formación y ordenación del clero, por lo cual fortaleció al seminario conciliar de la capital, elevó las exigencias de los candidatos al sacerdocio y promovió como nunca una mejor formación de curas expertos en las lenguas indígenas, consciente de que la mayor parte de su feligresía aún hablaba algún idioma nativo. En estos rubros hay indicios de que sí tuvo mejores resultados, a juzgar por la opinión 
de varios alcaldes mayores que, en la década de 1740, destacaron el buen desempeño de los curas seculares en la administración espiritual de los indios de sus partidos.

A fin de cuentas, puede decirse que Lanciego Eguilaz tuvo logros parciales en su empresa de mejorar la administración espiritual de los indios, pues las órdenes religiosas siguieron siendo un dique importante para la jurisdicción arzobispal mientras que, aunque Felipe $\mathrm{V}$ le dio un respaldo importante, frenó también su intento de secularizar sesenta doctrinas, con lo cual la Corona optó por suspender el inicio de una reforma eclesiástica de mayor envergadura. Con todo, los esfuerzos del arzobispo Lanciego dejaron apuntadas las líneas de acción para una futura reforma, que tuviera en la cuestión indígena y su religiosidad uno de sus puntos nodales.

\section{REFERENCIAS}

Acosta, José de (1954). Predicación del evangelio en las Indias. En: Francisco Mateos (ed.). Obras del padre José de Acosta. Madrid: Atlas. Disponible en: $<$ http://www.cervantesvirtual.com/obra/predicacion-del-evangelio-en-las-indias--0/>. Consulta: 1.8.2019.

Aguirre Salvador, Rodolfo (2000). «El ascenso de los clérigos de Nueva España durante el gobierno del arzobispo José Lanciego y Eguilaz». Estudios de Historia Novohispana, núm. 22, pp. 77-110.

Aguirre Salvador, Rodolfo (2002). «Grados y colegios en la Nueva España. 1704-1767». Tżintžun, núm. 36, pp. 37-42.

Aguirre Salvador, Rodolfo (2006). «El ingreso al clero desde un libro de exámenes del arzobispado de México, 1717-1727». Fronteras de la Historia. Revista de Historia Colonial Latinoamericana, vol. 11, pp. 201-230. 
Aguirre Salvador, Rodolfo (2008). «La secularización de doctrinas en México: realidades indianas y argumentos de Madrid, 1700-1749». Hispania Sacra, vol. 60, núm. 122, pp. 487-505.

Aguirre Salvador, Rodolfo (2012). Un clero en transición. Población clerical, cambio parroquial y política eclesiástica en el arzobispado de México, 1700-1749. México: IISUE; Bonilla y Artigas; Iberoamericana-Vervuet.

Aguirre Salvador, Rodolfo (2018). Cofradias y asociaciones de fieles en la mira de la Iglesia y de la Corona. Arzobispado de México, 1680-1750. México: Instituto de Investigaciones sobre la Universidad y la Educación.

Aguirre Salvador, Rodolfo (coord.) (2016). Visitas pastorales del arzobispado de México, 1715-1722. 2 vols. México: Instituto de Investigaciones sobre la Universidad y la Educación.

Bravo Rubio, Berenise y Marco Antonio Pérez Iturbe (2016). «Una práctica, un manuscrito: Los libros de visitas pastorales de José de Lanciego y Eguilaz al arzobispado de México (1715-1722)». En: Rodolfo Aguirre Salvador (coord.). Visitas pastorales del arzobispado de México, 1715-1722. México: Instituto de Investigaciones sobre la Universidad y la Educación, vol. I, pp. XLI-LVIII.

Castellano, Juan Luis (2004). «La exaltación dinástica». En: Eliseo Serrano (ed.). Felipe V y su tiempo. Madrid, Institución Fernando el Católico, pp. 930-955.

Concilio de Trento (1785). Sacrosanto, ecuménico y general concilio de Trento. Traducido al idioma castellano por don Ignacio López de Ayala. Madrid: Imprenta Real.

Concilium Limense Tertium (2007). En: Manuscritos del concilio tercero provincial mexicano (1585). Edición, estudio introductorio, notas, versión paleográfica y traducción de textos latinos por Alberto Carrillo Cázares. Tomo 2, vol. II, pp. 627-753.

Chávez Sánchez, Eduardo (1996). Historia del Seminario Conciliar de México. 2 tomos. México: Porrúa. 
Chuchiak, John F. (2014a). «Colonial Maya Religion and the Spanish World: The Role of "Idolatry" in InterEthnic Relations in Colonial Yucatán, 1545-1820». Axis Mundi: Journal of the Slovak. Association for the Study of Religion, vol. 9, núm. 1, pp. 47-66.

Chuchiak, John F. (2014b). «El Provisorato de Indios y la extirpación de la idolatría, 1563-1763». En: Sergio Quezada, Inés Ortiz Yam y Jorge Castillo Canché (eds.). Historia General de Yucatán: Yucatán en el orden colonial 1517-1811. Mérida: Universidad Autónoma de Yucatán, vol. 2, pp. 177-264.

Domínguez Ortiz, Antonio (1992). La sociedad española en el siglo XVII. 2 volúmenes. Granada: Universidad de Granada.

Escamilla GonZÁlez, Iván (2001). «La memoria del gobierno del virrey duque de Alburquerque, 1710». Estudios de Historia Novohispana, núm. 25, pp. 157-178.

Gonzalbo, Pilar (1998). Familia y orden colonial. México: El Colegio de México.

Lara Cisneros, Gerardo (2014). ¿Ignorancia invencible? Superstición e idolatría ante el Provisorato de Indios y Chinos del Arzobispado de México en el siglo XVIII. México: Universidad Nacional Autónoma de México.

Martínez López-Cano, Pilar (coord.) (2004). Concilios provinciales mexicanos. Época colonial. Disco compacto. México: Instituto de Investigaciones Históricas-UNAM.

Martínez López-Cano, María del Pilar y Francisco Javier Cervantes Bello (coords.) (2005). Los concilios provinciales en Nueva España. Reflexiones $e$ influencias. México: Instituto de Investigaciones Históricas; Universidad Nacional Autónoma de México; Benemérita Universidad Autónoma de Puebla.

Menegus, Margarita y Rodolfo Aguirre Salvador (2006). Los indios, el sacerdocio y la Universidad en Nueva España. Siglos XVI-XVIII. México: Centro de Estudios sobre la Universidad/Plaza y Valdés. 
RECOPIL ACIÓN (1987 [1681]). Recopilación de leyes de los reynos de las Indias. México: Escuela Libre de Derecho; Miguel Ángel Porrúa.

Ricard, Robert (1986). La conquista espiritual de México. Ensayo sobre el apostolado y los métodos misioneros de las órdenes mendicantes en la Nueva España de 1523-1524 a 1572. México: Fondo de Cultura Económica.

Solís RobledA, Gabriela (ed.) (2003). Contra viento y marea. Documentos sobre las reformas del obispo Juan Gómez de Parada al trabajo indígena. Mérida: CIESAS; Instituto de Cultura de Yucatán; Editorial Pareceres.

TAvÁrez Bermúdez, David (2012). Las guerras invisibles. Devociones indígenas, disciplina y disidencia en el México colonial. Oaxaca: El Colegio de Michoacán; CIESAS; UAM-I; Colegio Mexiquense.

Vos, Jan de (ed.) (2011). La guerra de las dos vírgenes. La rebelión de Los Zendales (Chiapas, 1712), documentada, recordada, recreada. México: UNAM; CIESAS; UNICACH.

Yannakakis, Yanna P. (2006). «Hablar para distintos públicos: testigos zapotecos y resistencia a la reforma parroquial en Oaxaca en el siglo XVIII». Historia Mexicana, vol. LV, núm. 3, pp. 833-893.

Fecha de recepción: 17 de diciembre de 2019.

Fecha de evaluación: 1 de octubre de 2020.

Fecha de aceptación: 2 de octubre de 2020.

Fecha de publicación: 30 de junio de 2021.

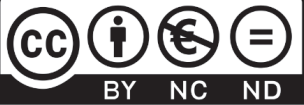

